\section{GP272 TRENDS IN THE MANAGEMENT AND OUTCOMES OF BABIES VENTILATED FOR MECONIUM ASPIRATION SYNDROME IN A TERTIARY NEONATAL INTENSIVE CARE UNIT}

Anurag Girdhar*, Shree Vishna Rasiah. Birmingham Women's and Children's NHS Foundation Trust, Birmingham, UK

10.1136/archdischild-2019-epa.331

Background Meconium aspiration syndrome remains a condition still encountered in the neonatal intensive care units resulting in significant morbidity and mortality among term neonates. With advances in neonatal intensive care management, the outcomes of babies with meconium aspiration syndrome have improved significantly. These include the use of high frequency ventilation with inhaled nitric oxide. This has significantly reduced the need to send these babies for extracorporeal membrane oxygenation (ECMO) treatment.

Aims To review the management and outcomes of babies ventilated for meconium aspiration syndrome in a tertiary neonatal intensive care unit (NICU).

Methods We retrospectively searched the Badger electronic patient record for all babies with a diagnosis of meconium aspiration syndrome in the last 9 years between 01/01/2010 and $31 / 12 / 18$. We then selected all ventilated babies with meconium aspiration syndrome for this review. A structured excel spread sheet was used to collate and analyse the data.

Results In the last 9 years there were 77 ventilated babies who had a diagnosis of meconium aspiration syndrome assigned to their badger electronic patient record. 59 were inborn and 18 were outborn babies. The median gestation age was 40 weeks with a range between 35 and 42 weeks. The median birth weight was 3470 grams with a range between 1836 grams and 4850 grams. 47 babies were managed with conventional ventilation and 30 babies were on high frequency ventilation. 38 babies received surfactant as part of their treatment for meconium aspiration syndrome. 37 babies also received inhaled nitric oxide. 43 babies had inotropic support. 3 babies had ECMO. One was an inborn baby referred for ECMO in 2014. The other two were out-born babies transferred back to the NICU following ECMO for on-going management. All 3 babies who went for ECMO were discharged home. 2 babies died in the last 9 years (2014 and 2015) but these were attributed to their neurological conditions.

Conclusion The outcomes of babies ventilated for meconium aspiration syndrome are good despite the serious nature of the disease. Swift escalation of the management of persistent pulmonary hypertension of the newborn (PPHN) is the key to reducing morbidity and mortality. With advances in the management of PPHN, we had only referred one inborn baby for ECMO in the last 9 years for meconium aspiration syndrome. The results of this review provide guidance when counselling these traumatised parents of babies ventilated for meconium aspiration syndrome.

\section{GP273 CORKAMBI: ONE YEAR OUTCOMES OF ORKAMBI ON CYSTIC FIBROSIS PAEDIATRIC PATIENTS IN CORK UNIVERSITY HOSPITAL}

Roisin O'Neill*, Muireann Ni Chroinin, David Mullane. Paediatric Cystic Fibrosis Department, Cork University Hospital, Cork, Ireland

10.1136/archdischild-2019-epa.332
Introduction Orkambi (Lumacaftor/Ivacaftor) was first introduced for use in the Cystic Fibrosis population in Ireland in 2017. It is only licensed for those patients who are homozygous for the F508del gene mutation.Orkambi was originally approved for children aged 12 years and older in 2017 and then this was extended for those aged 6-11 years old in 2018. Recently, the EMA(European Medicines Agency) has approved use for children 2-5 years. CUH(Cork University Hospital) looks after 98 paediatric patients with CF of whom 37 have been commenced on Orkambi since July 2017.

Objectives The primary objective was to assess the outcomes of Orkambi at 6 and 12 months on FEV1, BMI and BMI Centile and to compare the days on Intravenous antibiotics and weeks of oral antibiotics for pulmonary exacerbations in the year before and after commencing Orkambi.

Results Thirty seven patients were included in the study population with a split of 21 females and 16 males. The average profile of our patient cohort before commencing Orkambi was 11.0 years, BMI $16.8 \mathrm{~kg} / \mathrm{m} 2$, BMI Centile 43.2 and Average FEV1 96.7\%. To date, 11 patients have completed over a year of treatment and the remainder will have completed 12 months by June 2019. Six month followup has shown that $30 / 37(81 \%)$ of patients have had an increase in their BMI with an average BMI at 6 months of 17.5 and BMI difference of $+0.7 \mathrm{~kg} / \mathrm{m} 2$. BMI centile was increased in $24 / 37(65 \%)$ with centile difference of +5.7 to an average of 48.9. Lung function did not show any improvement from Pre-Orkambi values with average FEV1 of $95.9 \%$ at 6 months. This was also shown in followup of patients who completed 12 months of treatment with average FEV1 difference of $-2 \%$. For those who had completed 12 months on Orkambi, the no of weeks on oral antibiotics and IV antibiotics both showed a reduction in the year following commencement. There was a $26 \%$ decrease in oral antibiotics prescribed with average reduction of 1.5 weeks. Three patients had required IV antibiotics in the year prior. Two of these had no IVs over the following year and one patient with severe CF disease had a 55\% reduction in days on IVs from 121 to 66 days.

Conclusion Orkambi has improved BMI/BMI centiles but has not shown any improvement in FEV1. Preliminary data has shown a reduction in pulmonary exacerbations although further analysis of the remaining patients will allow more accurate conclusions.

\section{GP274 LIVER TESTS IN F508DEL HOMOZYGOUS CYSTIC FIBROSIS PATIENTS ON ORKAMBI}

Felicia Paluck*, Barry Linnane. University of Limerick, Limerick, Ireland

\subsection{6/archdischild-2019-epa.333}

Aims Cystic Fibrosis (CF) is an inherited condition causing complex, multi-system disease. Ireland has the highest incidence of CF in the world, where one in 19 people carry a defective gene. The most common detected Cystic Fibrosis Transmembrane Conductance Regulator (CFTR) mutation in Ireland is the F508del. In 2016, 55\% of patients were homozygous for F508del. Orkambi is a combination of Lumacaftor and Ivacaftor, and is licensed in the treatment of F508del homozygous CF patients. In patients taking Orkambi, serious adverse reactions related to elevated liver transaminase levels have been reported. It is recommended that ALT, AST and bilirubin are monitored every three months for the first year 